\title{
La mirada imperial y su desplazamiento hacia los espacios de confín: el caso de la narrativa de viaje de Florence Dixie a Patagonia
}

The Imperial Gaze and Its Displacement Towards the Border Spaces: The Case of the Narrative Travel of Florence Dixie to Patagonia

\author{
Oriette Sandoval-Candia* \\ Doctoranda en Ciencias Humanas \\ Universidad Austral de Chile \\ osand002@gmail.com
}

El presente artículo desarrolla una lectura desde la mirada imperial a la narrativa de viaje a Patagonia de Lady Florence Dixie, A través de la Patagonia, que tuvo lugar en $1879 * *$.

A partir de esta categoría de análisis, se da cuenta de los tropos que subyacen a esta forma de representación jerarquizada; el desplazamiento hacia contraespacios (espacios de confín) definidos como alternos a la modernidad, desde una dimensión espacio-temporal, la representación sublime y a veces ominosa de esta "otra" naturaleza y sus habitantes, y la sensación de extrañamiento que surge en el contacto con lo ajeno, lo no familiar, en este locus utópico y a la vez heterotópico de Patagonia, en el que es posible proyectar y experimentar sensaciones reprimidas de la vida moderna.

Palabras claves: Patagonia, narrativa de viaje, heteropía, mirada imperial.

This article develops a reading from the imperial gaze in the narrative of Lady Florence Dixie's voyage to Patagonia, Across Patagonia, which took place in 1879.

From this category of analysis, we realize the tropos that underlie this form of hierarchical representation; the displacement towards counter-spaces (border space) defined as alternative to modernity, from a space-time dimension, the sublime and sometimes ominous representation of this "other" nature and its inhabitants, and the sense of estrangement that emerges in contact with the foreign, the unfamiliar, in this utopian and at the same time heterotropic locus of Patagonia, upon which it is possible to project and experience repressed sensations of modern life.

Keywords: Patagonia, travel narrative, heterotropic, imperial gaze.

\footnotetext{
* Magíster en edición de libros, UDP/UPF, becaria doctoral CONICYT, el presente trabajo forma parte de la investigación doctoral "La construcción discursiva del estrecho Patagónico, entre los siglos XVI al XIX como un espacio natural y territorio de dominio, a través de la lectura de los proyectos de colonización: imperial, misionero y nacional, inscritos en las narrativas de viaje".

** Relato publicado originalmente en inglés "Across Patagonia", Richard Bently, London 1880.
} 
Al iniciar la lectura del libro de Florence Dixie, A través de la Patagonia (Dixie, 1996) ya aparecen enunciadas características presentes en las narrativas de viaje a los espacios de confín, el juego intertextual de imágenes y de lecturas de viajeros que han estado allí antes, movilizando representaciones estereotipadas de aquellos "otros lugares" hacia los lectores del mundo europeo:

\begin{abstract}
"iPatagonia! ¿Quién pensaría jamás ir a un lugar así?". "iSerás devorada por los caníbales!". "¿Por qué razón escoge un lugar tan apartado del mundo para ir?". "¿Cuál puede ser el atractivo?". "Está a miles de millas de distancia y nadie ha estado allí antes, excepto el capitán Musters y uno o dos aventureros locos!".

Oí, estas y otras preguntas y exclamaciones de los labios de mis amigos y conocidos cuando les conté mi intención de viajar a la Patagonia, la Tierra de los Gigantes. La Tierra de la mística Ciudad de oro de Manoa. ¿Cuál era la atracción de ir a un lugar tan apartado y a tantas millas de distancia? La respuesta estaba implícita en sus propias palabras. Lo escogí precisamente porque era un lugar exótico y lejano. Hastiada momentáneamente con la civilización y su entorno, quería escapar a algún lugar donde pudiera estar lo más alejada de ella como fuera posible" (Dixie 1996: 17-18).
\end{abstract}

Tierra de Gigantes, tierra de la mística ciudad de oro, pero ¿cuál es la atracción que subyace a estas insinuantes representaciones para ir a un lugar así? Lo había escogido, dice Florence, por ser un lugar exótico y lejano, marcando desde el inicio el lugar de enunciación, desde el centro del mundo se desplaza hacia la periferia, distinción arbitraria e imaginada desde la que se articula la frontera geoespacial del proyecto moderno. Siguiendo a E. Said, dicha arbitrariedad radica justamente en que "[...]la geografía imaginaria que distingue entre 'nuestro territorio y el territorio de los bárbaros' no requiere que los bárbaros reconozcan esta distinción. A 'nosotros' nos basta con establecer esas fronteras en nuestras mentes; así pues 'ellos' pasan a ser 'ellos' y tanto su territorio como su mentalidad son calificados como diferentes a los nuestros" (Said 1990: 80).

La búsqueda de lo exótico y el alejamiento del locus moderno son elementos recurrentes en las narrativas de viaje a los espacios situados en los márgenes de los imperios. De esta forma, el viajar se constituye a partir de un doble desplazamiento: espacial y temporal, movilizándose corporal y mentalmente a lugares considerados bajo esta narrativa evolucionista como premodernos.

La narradora busca escaparse hacia un "otro lugar'" en el que pueda proyectar su deseo, la fantasía que ha surgido de su lectura de la caza en Patagonia. Es la travesía hacia un contraespacio, siguiendo la terminología foucaultiana, la búsqueda de un lugar heterotópico, es decir, un lugar (topos) contrapuesto, diferente (hetero) al locus moderno, lugares que son reales, 
que se han diseñado en la "institución misma de la sociedad, que son especies de contraemplazamientos, un tipo de utopías efectivamente realizadas, en las que todos los demás lugares reales [...] que se pueden encontrar en el interior de la cultura están a la vez representados, cuestionados e invertidos"; continúa Foucault: "especie de lugares, que están fuera de todos los lugares no obstante son efectivamente localizables. Estos lugares, porque son absolutamente otros que todos los emplazamientos que reflejan y de los que hablan, los Ilamaré, por oposición a las utopías, las heterotopías" (Foucault 2004: 15; trad. O.S.C.).

Este nuevo espacio de destino es registrable en el mapa, tiene una localización, es real, Patagonia, al que se llega siguiendo un itinerario concreto, una ruta de tráfico ya trazada tres siglos antes por las expediciones de ultramar, que abrieron la conexión interoceánica desde el Atlántico al Pacífico: Europa, bahía -el primer desembarco en América- cuyo sentido del olfato fue agredido por los olores de los "otros", los miasmas de los esclavos, continuando hacia la costa de Mar del Plata, en la que tuvo que realizar una odiosa cuarentena, por venir de las zonas tórridas plagadas de fiebre amarilla o vómito negro, y por fin, arribar a la colonia de Punta Arenas, "el hoyo desamparado de Dios" (Dixie 1996: 45). Y a la vez, este espacio es representado inversamente como un locus utópico, que le va a permitir satisfacer el deseo de una jornada de caza libre, sin cuotas de caza, ni en espacios previamente delimitados, al igual como se escenifican imaginariamente en los grabados de la narrativa de Musters, que ella ha leído y transportado en su viaje ${ }^{1}$. Y porque, a pesar de que existen regiones más favorecidas por su naturaleza exótica, ella añade a Patagonia las características de "vastedad" y aparente "vacío", objetivando esta representación imaginaria y fundante para la literatura patagónica bajo el registro técnico: "Sin duda hay regiones salvajes más favorecidas por la naturaleza en muchos aspectos. Pero en ningún otro lugar está uno tan completamente a solas. En ningún otro lugar hay un área de 100.000 millas cuadradas sobre las que se pueda galopar" (Dixie 1996: 18).

Así, los lugares de confín en el que se inscribe Patagonia, funcionarían como un espejo al proyecto moderno, en el cual validar su antinomia entre sus espacios civilizados y los "otros" bárbaros, un lugar de proyección, a la vez heterotópico y al mismo tiempo utópico, y, retomando a Foucault, en este espacio "habría sin duda una suerte de experiencia mixta, medianera que estaría dada por el espejo. El espejo es una utopía, porque es un lugar sin lugar. En el espejo, me veo donde no estoy, en un espacio irreal que se abre virtualmente detrás de la superficie, estoy allá, allá donde no estoy, especie de sombra que me devuelve mi propia visibilidad, que me permite mirarme allá donde estoy ausente: utopía del espejo. Pero es igualmente una heterotopía, en la medida en que el espejo existe realmente y tiene, sobre el lugar que ocupo, una especie de efecto de retorno; a partir del espejo me descubro ausente en el lugar en que estoy, porque me veo allá" (Foucault 2004: 15; trad. O.S.C).

\footnotetext{
1 Se refiere al libro del capitán George Musters: At home with the Patagonians: A year's wanderings over untrodden ground from the Straits of Magellan to the Rio Negro, publicado en 1871 por el influyente editor de viajes, el británico John Murray.
} 
Así, el cambio del mar a tierra firme lo experimenta Florence como un alejamiento del mundo civilizado, una proyección de sí misma en un lugar del que no forma parte, es su presencia en lo ausente, apareciendo en ella ese sentimiento de inquietante extrañeza, desde donde convierte en "otro" el lugar que experimenta como ajeno.

Durante el episodio del desembarco desde este espacio móvil, representado por Foucault como la heterotopía por excelencia, "como un pedazo flotante de espacio, un lugar sin lugar, que vive por el mismo que está cerrado sobre sí y que al mismo tiempo está entregado al infinito del mar[...]" (Foucault 2004: 19; trad. O.S.C).

El barco, el Britannia, convertido y reconocible, casi uterino, en el que ha habitado por meses placenteramente bajo la indumentaria, ritos y modales de su clase, se ve irrumpido, casi como un parto, con la llegada a este lugar inhóspito, que le provoca ese sentimiento de extrañeza ante lo desconocido: "y ahora que se rompía el último eslabón que me unía a la vieja Inglaterra, por primera vez comencé a darme cuenta realmente de que nos encontrábamos a diez mil millas de nuestro hogar y de nuestros amigos, solos en medio de rostros desconocidos y paisajes deshabitados" (Dixie 1996: 46). Para compensar esta sensación de enajenación que inunda el lugar, Florence traslada costumbres cotidianas de su modo de vida aristocrática a este nuevo escenario, porque recordemos, su visión y construcción de aquella realidad paisajística es una mirada, una observación alejada del mundo de trabajo; es de ocio y caza en Patagonia. Raymond Williams nos orienta en este aspecto con su definición de paisaje sosteniendo que "el paisaje, tanto en su dimensión material como en su referencia literaria, es la producción de un tipo particular de observador, sustraído del mundo del trabajo. El paisaje es un punto de vista antes que una construcción estética" (Williams 2001: 10). Concretamente, para que sea posible dicha estetización de la naturaleza, es necesario desvincularlo de la fuerza del trabajo que lo origina. Así, sostiene respecto de la visión acerca del campo, este "nunca es paisaje antes de la llegada del observador ocioso que pueda permitirse una distancia en relación con la naturaleza" (Williams 2001: 10). En este caso, la pampa reemplaza al campo de la lectura de Williams, y emerge como escenario estético mediante la omisión, no de la fuerza del trabajo, sino de la invisibilización, la no presencia de los "otros", los indígenas que la habitan, que han sido clave para la sobrevivencia de la comitiva guiando su ruta de caza, que ahora desde este punto de vista, desde este "yo imperial", aparecen naturalizadas como nuevas sendas "descubiertas" en este vasto y desolado territorio. La narradora traslada el pícnic a este espacio alterno, bajo esta hermenéutica constante y fundante para la experiencia de alteridad de transformar lo extraño en familiar. Así, para recibir a unos especiales invitados en el campamento, el príncipe Enrique de Prusia y su comandante, escribe: "los recién llegados evidentemente encantados con nuestro acogedor y silvestre refugio y por lo novedoso del pícnic que difícilmente podrían haber imaginado hacer en Patagonia de entre todos los lugares del mundo" (Dixie 1996: 57). La escena campestre fue posible, porque fueron "ellos" los que llegaron al campamento y no, como temían que pudiese haber ocurrido, la aparición "de sanguinarios rebeldes" (Dixie,1996: 57) aventurando un segundo motín en la colonia de Punta Arenas, conocido 
el primero como "Motín de los Astilleros"2 ocurrido dos años antes de este viaje. Así, alejada la barbarie de los amotinados, se levanta el telón de la idílica cena en Patagonia. El pícnic representa la metáfora del trasplante, la autoafirmación del "yo", en medio del bosque, es marcar una frontera, como todas imaginarias, desde una práctica cotidiana del imperio en un lugar de confín, es movilizar la experiencia desde mi espacio a este "otro", sin posibilidad de que escurra. Así se deleita con el eco de procedencia de los sabores propios movilizados a este inusual encuentro: "bajo las hayas patagónicas y junto al cordero regional degustamos asperges en jus los cuales habían alcanzado su delicado sabor bajo el suave cuidado del verano holandés, patés elaborados muy lejos entre las azules montañas del Alsacia y características salchichas de la madre patria, aunque con poco sabor" (Dixie 1996: 60).

Poco a poco, estos "otros" espacios se van tornando en familiares, en espacios reconocibles, "civilizados", y a la partida, abriéndose camino por el espeso bosque de lengas, la narradora da una última mirada, para contener de alguna forma ese paisaje perdido:

Finalmente todo estuvo listo, montamos y con una última mirada al bosque de hayas que había sido nuestro campamento el cual se había vuelto bastante familiar y hogareño para nosotros, partimos, ahora definitivamente en camino, con rumbo a la tierra desconocida que yacía delante nuestro (Dixie 1996: 65).

La naturaleza de Patagonia continuamente desborda hacia lo extraño: "estuve un largo tiempo inmersa contemplando este extraño paisaje desolado, dejándome llevar por los misteriosos sentimientos y los extraños y fantásticos pensamientos que sugería" (Dixie 1996: 89). En un cuadro nocturno, Florence nos va describiendo sensitivamente bajo un orden aparente el estado del campamento, la disposición de los hombres, los animales y la naturaleza:

Alrededor de un enorme montón de troncos en llamas yacían los durmientes, con quienes extrañamente el azar nos había así reunido por una noche, en variadas posturas que sugerían un profundo descanso. Los perros habían despertado de su sueño y festejaban con cualquier hueso $u$ otro resto de la fiesta que lograban descubrir. Unos rayos de luna se filtraban a través de la espesura de las ramas y hojas encima nuestro, arrojando extrañas luces y sombras sobre el campamento y el extraño efecto de toda la escena era resaltado por el misterioso gemido de una guala que a intervalos llegaba flotando en el aire desde la laguna de abajo, como la voz de un espíritu inquieto (Dixie 1996: 61).

2 En 1851 se tiene antecedentes del primer motín ocurrido en la colonia de Punta Arenas, conocido con el nombre de "Motín de Cambiaso", para mayores antecedentes ver: Vicuña Mackenna (1877). 
Así también aparecerán, bajo esta estética propia del romanticismo desde el que se construye Patagonia como un escenario de valoración estética, mediante la representación en tanto "cuadros de la naturaleza", por medio de los binarismos: oscuridad/claridad, misterio/sorpresa, las Torres del Paine: desde la penumbra a la luz del sol, emergen como la aguja de Cleopatra de Londres, ciertamente en su forma rústica, como obeliscos de granito.

Siguiendo al filósofo iluminista Edmund Burke, el relato de lo sublime es también provocado por la vastedad, la grandeza (cfr. Burke 1997), en este caso atribuida a los Andes patagónicos:

Nos apuramos ansiosos de alcanzar la entrada al cañadón y avistar lo antes posible la tierra prometida, pero transcurrieron bastantes horas hasta que finalmente llegamos al punto más lejano y salimos de la penumbra a la luz del sol. Delante nuestro se extendía una pintoresca llanura cubierta de suave pasto y salpicada por aquí y por allá de grupos de hayas atravesadas en todas las direcciones por murmurantes arroyos. El fondo estaba conformado por cerros boscosos, detrás de los cuales se encumbraba nuevamente la cordillera. Tres altos picos de tinte rojizo y de la misma forma que la aguja de Cleopatra, constituían un aspecto sobresaliente del paisaje (Dixie 1996: 167).

\section{Extraña a mí misma. Ambivalencia del yo imperial colonial}

Pero esta categoría del extrañamiento no solo se da desde el exterior, desde la naturaleza, sino desde lo propio, en este caso, en el cuerpo. Julia Kristeva (1991) aborda el concepto de lo heimlich/unheimlich tomado del ensayo de Freud sobre "lo ominoso", en el que refiere a un concepto que vincula semánticamente lo familiar con su opuesto, lo no familiar, que asoma sorpresivamente en nuestra vida provocándonos esa inquietante extrañeza.

Es decir, la presencia de lo extranjero, lo no familiar, como fuente de lo ominoso, es esa experiencia de alteridad en la que reconocemos nuestro propio extranjerismo. Así indica Kristeva que "extraña también es esa experiencia del abismo entre yo y el otro que me choca, no la percibo siquiera, me aniquila tal vez porque la niego. Frente al extranjero que rechazo y con el que me identifico a la vez, pierdo mis límites, ya no tengo continente" (Kristeva 1991: 363). Es esta ambivalencia entre el "yo" y el "otro" la fuente de esa inquietante extrañeza, incertidumbre respecto de lo que somos, revelando esa tensión permanente entre lo mío y lo ajeno en la conformación de la subjetividad. Asimilación y diferencia respecto de lo "otro", lo que por un lado identifica y por el otro se teme. La fragilidad en la constitución de las identidades se revela, las categorías de género, nacionalidad, estatus, se vuelven difusas, "porosas".

De esta forma, al finalizar el viaje y ya a la espera del barco que los llevará de retorno a la civilización, Florence y su comitiva pasan la última noche en la casa de huéspedes, la posada en la Colonia de Punta Arenas. Ahora desplazada hacia este espacio interior, ella no se reconoce a sí misma, el espejo 
proyecta un no/yo: "nos hizo darnos cuenta de nuestro aspecto personal y el envidiable 'regalito' (el espejo) fue nuestro al vernos como los demás nos veían" (Dixie 1996: 244). Su presencia, desencajada con los signos de la civilización, la limpieza, el orden y los hábitos domésticos, es ahora extraña, porque ese "otro paisaje", la pampa de la Patagonia, los había convertido en los "otros"; durante la travesía de su viaje se habían metamorfoseado sin tener conciencia de ello, resultaban ser extraños y repulsivos a sí mismos, el color de la piel, su blancura se había oscurecido dramáticamente:

Nuestra apariencia y vestimenta con nuestra vida pasada en la Pampa, pero rodeada de limpieza y civilización quedaban decididamente fuera de lugar. Habíamos realizado nuestras abluciones como de costumbre y tan cabalmente como las circunstancias lo permitían, pero no habían permitido mucho. Los hombres del grupo sobre todo eran desagradables de mirar. El pelo les había crecido y estaban como duendes, las caras se habían bronceado de un oscuro rojizo que la tierra y el humo de tantas fogatas habían profundizado en un notorio negro, los mentones sin afeitar estaban desfigurados por el profuso crecimiento de una áspera barba cerdosa. Nuestras ropas no aguantaban una inspección profunda, la sangre de muchos guanacos, la grasa de muchas cenas de avestruz, las espinas de muchos calafates habían dejado sus marcas, y en conjunto era difícil de imaginar un lote más rufianesco y desgravado que el que parecíamos. Pero el agua caliente, jabón y afeitadoras y un cambio de indumentarias, hicieron maravillas y luego de un trabajo arduo de varias horas, cuando nos reencontramos no fuimos casi capaces de reconocernos (Dixie 1996: 245).

Esta transfiguración tiene posibilidad de ser en el imaginario de Florence solo de manera transitoria -a nivel de apariencia física-, a diferencia de la mutación del "excéntrico inglés llamado Greenwood"3 que se ha convertido en "salvaje", resultado de su condición de colono en su larga permanencia en la Pampa, y que según le rumorea uno de sus acompañantes "parecía llevar una vida de ermitaño. Había renunciado al mundo y sus cosas vanas incluso hasta el punto de despreciar las precarias comodidades de los otros habitantes de la pampa". Vestido de forma "primitiva" vagaba por las "laderas de la cordillera y en vez de hacer el viaje a la Colonia para comprar provisiones, pasa el año completo alimentándose simplemente solo de carne de guanaco y avestruz" (Dixie 1996: 135).

La narradora manifiesta su curiosidad de conocer al colono inglés, distinta a la que tiene respecto de los "indios". Mediante la distinción entre lo pasivo/activo, la narradora construye el orden de lo masculino indígena y lo

\footnotetext{
3 Acerca de la vida de este colono inglés en Patagonia ver sus memorias publicadas bajo el título: Patagonia Bravia. Naturaleza, vidas y aventuras Memorias Originales del baqueano William H. Greenwood, de Gladys G. Grace Paz y Duncan S. Campbell (2015).
} 
no indígena, de esta forma los habitantes de Patagonia son representados pasivamente bajo el tropo de la disposición, situándolos en una escala inferior del desarrollo humano -diacrónica-, acentuando la similitud de sus cuerpos con la morfología animal y que, inversamente, estos aparecen personificados, dotados "de mirada". Así, los guanacos tienen "los ojos grandes y hermosos y tienen una extraña mirada", su piel es de "textura lanuda" (Dixie 1996: 102), mientras que los indígenas carecen de piel, se presentan a su examen desde su "oscura cara sucia, cuyo principal rasgo era un par de penetrantes ojos negros" (Dixie 1996: 73).

De esta manera, los "otros" son accesibles a su mirada. Ha visto en su travesía a un "auténtico tehuelche" e, impactada por su bien parecido, decide su apropiación por medio de la representación visual, el retrato: "Impactada por su gracioso porte y bien parecido rostro le rogué al Sr. Beerbohm, que había traído un cuaderno de bocetos, que hiciera un bosquejo de este hermoso 'hijo de la pampa'"' (Dixie 1996: 82). Finalmente, cuando el dibujo estuvo terminado, "se lo pasó para que lo viera, su frente se contrajo airadamente y sus ojos mostraron una expresión de temor, emitió unos furiosos sonidos guturales y finalmente para nuestra rabia, rompió el retrato en pedazos". Según su interpretación, "Él tenía la impresión de que la finalidad del dibujo, era arrojar algún hechizo maligno sobre él y que le sucedería alguna desgracia si este no fuese destruido"(Dixie 1996: 82); esta representación concuerda con su visión imperial de que los indígenas no son portadores de saber, sino solo de "gentílicas supersticiones".

Disímil es la representación del colono inglés antes aludido por el que se siente atraída, no pudiendo sin embargo satisfacer su curiosidad, ya que, a pesar de haber dejado los indicios de las fogatas para indicar a Greenwood su paradero, la autonomía de este - posición activa- lo sitúa en el relato con la posibilidad de decidir si conocerla a ella o no:

Estaba interesada en esta especie de salvaje hombre de los bosques y mantenía atenta la mirada mientras viajábamos por esa región con la esperanza de verlo. Pero si alguna vez estuvo cerca nuestro y por lo tanto de las fogatas que ubicaban nuestra ubicación, nunca tuve la oportunidad de conocerlo, puesto que él no dejó de lado sus costumbres a favor nuestro (Dixie 1996: 135).

Esto confirma el marco interpretativo del determinismo geográfico desde el que se configura esta realidad, la influencia per se de la naturaleza de Patagonia en las características de los indígenas, y que también produce alteraciones en los hombres y mujeres como "ellos", que las han padecido de manera transitoria porque solo están de paso, no así en particular el colono inglés, que se ha convertido en un salvaje, autónomo -y casi erótico- personaje del bosque.

La estructura de la mirada imperial se despliega sobre los "otros", pero existe en esta misma narrativa una desarticulación transitoria, más bien una ilusión, cuando la narradora da cuenta de la curiosidad que sienten los "otros" los indígenas por ellos: "Cuando estuvo cerca nuestro detuvimos nuestros 
caballos para observarlo, para nuestra alegría lo miramos fijamente por algunos minutos, recibiendo por él un cuidadoso examen. Cualquiera fuesen sus pensamientos respecto a nosotros, lo encontramos muy poco atractivo". (Dixie 1996: 73) La mirada de los "otros" se caracteriza desde la indiferencia y la ausencia de emotividad; así, llegando al campamento indígena, señala:

Había alrededor de una docena de grandes tiendas de cuero, al frente de las cuales observaba nuestra llegada con indolente curiosidad una muchedumbre de hombres y mujeres[...]. Dos indios, más curiosos que el resto se acercaron a recibirnos, montando ambos en el mismo caballo y nos saludaron con mucha sonrisa y palabras ininteligibles. Luego de nuestra llegada fuimos rápidamente rodeados por una gran cantidad de curiosos, algunos de los cuales nos observaban con impasible gravedad, mientras otros reían y gesticulaban discutiendo nuestra apariencia en su burdo lenguaje gutural, con una forma vivaz que era una variante para la usual solemnidad de la mente india (Dixie 1996: 76).

En este cruce de miradas los "otros" nos miran con curiosidad, pero al no tener una lengua inteligible, es solo una mirada que la narradora otorga cierta "impasible gravedad", sin humanidad, recordar que los animales a ella también la miran de igual forma. En este espacio alterno -el campamento indígena-, se evidencia el juego de miradas, "nosotros" los miramos con curiosidad, a "ellos" les es posible mirarnos, eso sí, desde su mudo lenguaje, ausente de cultura. No hay comprensión, no existe la mirada mutua de sujeto a sujeto, sino de sujeto a objeto, desplegándose los estados de dominación simbólica por medio de esta, la mirada imperial.

\section{La dominación simbólica del mundo natural}

Dentro de las narrativas de viaje referidas a los espacios ubicados en los márgenes del imperio, definidas como de descubrimiento y exploración, encontramos en su escritura el uso de dispositivos retóricos en los que es visible la dominación de la naturaleza a nivel simbólico, la llamada gesta fundacional, que se construye en el relato mediante imágenes de posesión, que tienen lugar a la hora de desembarco, pisando tierra firme: la inmersión en el "nuevo" territorio de la espada, la cruz y la bandera, con el consiguiente acto de nominación de lo visible. De esta manera, la apropiación de lo hasta entonces no conocido se despliega bajo la autoría de este "yo imperial" que ha proyectado su deseo de posesión en este espacio alterno. Para este tipo de registro, y analizando la retórica victoriana del descubrimiento, Mary Louise Pratt señala la figura del "pintor verbal", el que "debe convertir en enormemente significativo algo que es, sobre todo desde un punto de vista narrativo, prácticamente un no-hecho" (Pratt 2010: 365). Siguiendo a Pratt, esta operación de dominación por medio de la mirada se desplegaría a nivel discursivo bajo tres estrategias retóricas: la estetización del paisaje, la densidad de significado mediante el uso de modificadores de los adjetivos, y finalmente, la relación de dominio que se predica entre el que ve y es visto. Así lo manifiesta analizando una narrativa de viaje al África ecuatorial: 
Una vez más están presentes muchos elementos estándar del tropo imperial: la apropiación del paisaje, los adjetivos estetizantes, el amplio panorama anclado en el contemplador; veedor. Pero tan pronto como los ojos se posan sobre el "objeto de sus deseos", una fantasía intervencionista desplaza completamente la realidad del paisaje que se extiende ante él, y esa fantasía se convierte en el contenido de la visión (Pratt 2010: 376).

En el caso de Florence, estas categorías igualmente se visibilizan en su narrativa según este movimiento de descripción-posesión del nuevo espacio develado bajo esta mirada que se resume bajo la retórica del "soy monarca de todo lo que veo" (Pratt 2010: 363):

El campo que estábamos ahora atravesando era totalmente diferente al que habíamos dejado atrás. No se veía ni un solo árbol o arbusto por ningún lado y mientras que a nuestra izquierda yacía el escarpado cordón de la serranía, al frente y a la derecha una inmensa planicie se extendía hasta el horizonte elevándose y cayendo ocasionalmente en leves ondulaciones, que de no ser así se presentaría completa y monótonamente plana. El suelo que era bastante pantanoso estaba cubierto por un abundante pasto grueso y verde entre el cual podíamos ver bandadas de gansos salvajes pastando en gran número. Pasamos numerosas lagunas de agua fresca cubiertas de aves silvestres, las cuales levantaron vuelo alocadamente ante nuestra llegada. Uno o dos halcones revoloteaban ocasionalmente sobre nuestras cabezas, y una vez los perros partieron en persecución de un pequeño zorro gris que había aparecido incautamente, pero con excepción de estos no había señales de vida animal en la silenciosa y aparentemente interminable Ilanura en frente nuestro (Dixie 1996: 66).

De igual forma, a veces encontramos en la narrativa de su viaje la presencia de la mirada masculina de dominar y conquistar esta "tierra virgen", aludiendo a la metáfora sexual de dominar y conquistar el cuerpo femenino: "A estos atractivos se sumaba el pensamiento siempre tentador y grandioso para una mente activa, de que allí podría penetrar en vastas regiones salvajes, vírgenes aún al paso del hombre" (Dixie 1996: 19), buscando desde allí construirse heroicamente en este espacio del afuera. Durante las escenas de caza, ella se mueve desde ser solo espectadora de las pericias de sus compañeros, hacia convertirse por azar en la heroína de la jornada:

Me levanté en un segundo, a tiempo de verlo brincando hacia un lejano acantilado llevándose consigo mi esperanza de ser la heroína del día. No quedaba más que caminar hasta mi caballo y ver qué había sido de mis compañeros[...]. Repentinamente otro jinete apareció en el llano $y$ el infortunado guanaco tuvo que girar bruscamente a 
la izquierda, movimiento que "hurra" lo trajo casi frente a donde yo estaba. O sea, que debía cruzar el acantilado en algún punto en una línea entre el recién llegado y yo; los otros jinetes por la forma en que se había llevado a cabo la carrera formaban un círculo a su espalda que impedía su escape en cualquier otra dirección. Viendo esto, desbordante de alegría, hundí las espuelas en mi caballo y volé paralelamente al borde del acantilado y los jinetes por el otro lado hicieron lo mismo para cerrarle el paso y echarlo hacia sus enemigos de la retaguardia (Dixie 1996: 100-102).

Es la mirada el acto de posesión, tanto del espacio como de los animales. Siguiendo a John M. Mackenzie, refiriéndose al control del espacio natural mediante los "deportes campestres" incitados por las guías de viaje británicas a la India, señala que "en una paradoja intrigante, los bosques y cotos de caza eran tierras vírgenes fuera de los límites de la civilización, pero por ello atractivas y fascinantes". En concreto, las reservas forestales y la caza como práctica cultural "servían para tender la red imperial sobre ellas", y en este sentido, "el manual era algo más que una guía de viaje", pues "era la incesante textualización del dominio y el control, expresados a través de los lugares, incidentes y formas tanto pasadas como presentes, mediante las cuales se manifestaba descollantemente ese poder imperial" (Mackenzie 2005: 226).

La dominación se inicia sensorialmente. Hay algo en la naturaleza no visto antes, la novedad de la fauna asoma desde un sonido crujiente, apareciendo el ciervo dorado de Patagonia, personificado, otorgándole una actitud frente a ella, cierta mirada "de inquisitiva curiosidad" (Dixie 1996: 184), pero que igualmente está a disposición de su deseo de apropiación material, en la práctica de exhibición de lo exótico, de decorar con la cabeza embalsamada del ciervo las paredes de su residencia:

De inmediato me atrajo un sonido crujiente como de palos quebrándose cerca de mío. Mirando en la dirección de donde venía el sonido, vi una especie de ciervo de color dorado oscuro mirándome con gran asombro. Era un espléndido macho, con hermosas astas ramificadas y grandes y oscuros ojos lánguidos. Cerca detrás de él, se asomaban con cuidado dos hembras y un poco más lejos pude divisar varios otros animales de la misma clase. iCómo anhelaba tener un rifle! [...]. No perdí tiempo en informarles del descubrimiento que había hecho y tomando mi revolver procedí alcanzar de nuevo lo más silenciosa y clandestinamente [...]. Sí, ahí estaba, un hermoso animal, aún en la misma actitud de inquisitiva curiosidad en que lo había dejado. Ansiosa de evitar dañar la cabeza, apunté detrás del lomo y disparé (Dixie 1996: 184).

Regreso al inicio de la obra, al sugerente grabado de Julius Beerbohm, ingeniero parte de la comitiva de Florence, que se ha elegido para la portada 
del libro en su edición traducida al español. En el dibujo está presente ese cruce de miradas, que ha sido leído bajo la obra pictórica Las Meninas de Velázquez por Mónica Szurmuk (2007):

Florence Dixie hace una apuesta fuerte por un modelo de representación en el que el punto de vista es el de los que observan, pero también incluye a los observadores. Por un lado, incluye a ella misma observando; por el otro, algo sorprendente: una mujer india que observa hacia un afuera del cuadro (¿a nosotros?) [...]. Florence leyendotraduciendo la experiencia tehuelche. Ella, la inglesa entre los salvajes y las salvajes. Mujeres que miran mujeres, cruce de miradas, miradas cruzadas (p. 29).

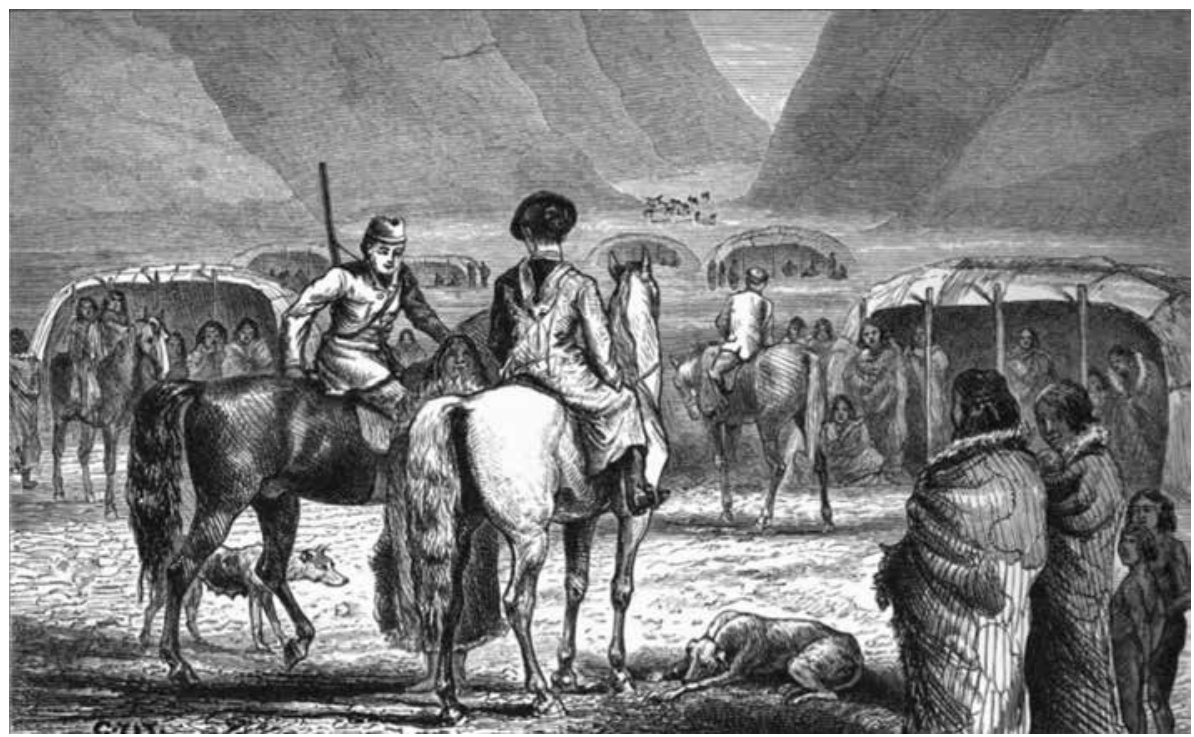

Figura 1: Campamento aonikenk. Ilustración de Julius Beerbohm (Dixie1880: 64).

Para mi lectura, destaco en esta imagen ese cruce de miradas, por sobre todo porque veo en ella el indicio de la mirada del "otro", de las "otras", sobre "nosotras" las lectoras en la composición de estos distintos planos: en el primero al fondo se ven la chozas y caballos ubicados a un mismo nivel, junto con los tehuelches forman parte del paisaje [propio de la representación colonial]; luego está un segundo plano, en que se distinguen los habitantes del campamento y su interacción con parte de la comitiva, que pretende abastecerse de alimentos para el resto del viaje; en el centro, como punto de interés compositivo de la imagen nos encontramos con la narradora, que mira en picado a una o un tehuelche que la mira, mientras cruza la mirada otro integrante de la comitiva, que bien podría ser un soldado, ambos la circundan y delimitan su espacio de movimiento; luego en un plano más próximo por un momento el punto de interés de la imagen se desplaza hacia la mirada de fuera de campo, de una mujer tehuelche que nos interpela, haciéndonos 
partícipes de la escena. Y recuerdo la interrogante clave de Spivak (1998) ¿puede hablar el subalterno? Para nuestro caso, se nos abre una perspectiva de reflexión sobre la mirada y la construcción de alteridad que se da en las narrativas de viaje a los espacios de confin ¿Puede mirar el subalterno? ¿Bajo qué tipo de relación se articularía? ¿Desde dónde?

Para aproximar mi respuesta, veo en la recuperación tanto de la memoria indígena desde la oralidad, entendida esta como una forma de relato polifónico, y en la atención cuidadosa a la lectura del "relato de orilla", ese testimonio de borderline presente en la narrativa oficial, una forma de recuperar los trazos de esta mirada ausente. En la narrativa de viajes a Patagonia, desde las fundacionales a las contemporáneas, se puede encontrar la voz, el conocimiento de la naturaleza de los "otros" "otras" que son escuchados, pero no está inscrito su "yo" en el relato, asoma en la escritura solo como "oído" por el "yo" colonizador. Este conocimiento profundo, resultado de la vivencia del habitar un espacio geográfico ya trazado durante siglos, es usado, invisibilizado, transformado en un registro de tipo funcional, destinado a la orientación de rutas y pasos, que paradójicamente se "descubren".

La recuperación de la mirada subalterna, en este caso la indígena, pasaría entonces por recuperar esa visión cultural de la naturaleza puesta en los márgenes: la visión insular, el archipiélago como un mundo intrincado, profundo de sentido, anudado y registrado en la memoria nómade. Es en definitiva la desarticulación, la reescritura de nuestra mirada, y entonces me detengo en esta especie de "alero" movedizo de mi propio nomadismo como lectora, tomando como referencia pasajes de la narrativa de viaje en Patagonia de una mujer indígena kawésqar, Gabriela Paterito (2013), quien alude a un "otro" "lugar de ciervos":

"Alojé en la bahía de Kalau, en esa bahía estuve varios días, los ciervos que se habían tirado al agua los trozamos y comimos, sus pieles este que... les sacamos cor ... sec ... quedaron puestas a secar en el bastidor ahí, y, y en otro lugar, en otro lugar, anduve a los ciervos, ahí comimos muchos ciervos en ese lugar.

Yo no conocía los ciervos, no los imaginaba, ya que siempre anduve en el mar de la costa exterior y ahí navegaba siempre. En la costa interior que [así] llaman, en cambio, como así se llama este que... es lugar de ciervos, y lugar donde andan ciervos.

Se iba a cazar ciervos en embarcación y se los buscaba para comer y llegábamos ahí a remo. En esa bahía estuvimos, las pieles que se habían puesto en el bastidor para secar, se usaban como colchón, eran colchones que dejábamos abajo [en el suelo; O.S.C.] y que se habían dejado secar [antes], ahí se dejaban.

Se sentía resbaloso cuando me manda... me acostaba ahí una vez desplegada, cosida y secada en el bastidor 
de pal... palito, varas de palo este que... varas de sauco, cosido con junquillo en el bastidor y que después se ponía a secar. Y era mi colchón, en él yo me acostaba[...]" (Aguilera O. y Tonko J. 2013: 121-122).

Aquí y allá, desde la mirada a los ciervos de Florence y Gabriela, nos desplazamos por las distintas formas de representar lo natural que ambas narradoras manifiestan en su relato de viaje, articulándose entre el conocer/ develar y las formas de imaginación que ambas manifiestan de este animal. En el caso de Florence, ella mitifica el encuentro como una aparición (no ha visto este tipo de especie antes) del "ciervo dorado", ella devela algo que estaba, pero no se había descubierto antes de su mirada, su registro imperial. Su imaginación ha proyectado el cadáver desde lo estético, como un adorno embalsamado, un hito de su caza, ocultando el procesamiento del disecado, embalsamado de este cuerpo "que no quiere dañar" (Dixie 1996 p. 184). En tanto que, para la narradora Kawésqar, Gabriela, su apropiación tiene que ver con lo práctico y lo concreto, hace uso del ciervo para alimentarse y dormir; nos da detalle de la fabricación de colchones describiendo la técnica de secado de la piel de este animal, que ella encuentra sensitivamente "resbalosa". Ella nunca había visto ciervos antes "yo no conocía los ciervos, no los imaginaba, ya que siempre anduve en el mar de la costa exterior y ahí navegaba siempre" (Aguilera O, y Tonko J. 2013 p. 121);su imaginación, su mirada no registra una nueva especie.

En el relato de Gabriela, no hay un "yo" imperial, hay una voz en plural, un conocimiento que restituye un indicio en la geografía "lugar de ciervos", "lugar donde andan ciervos", ubicado en la costa interior de Patagonia, espacio que igualmente ha transitado Florence, experimentando su propia alteridad en la mirada sobre los "otros" y esa "otra" naturaleza que rememora en su escritura situada, en su "espacio propio", Londres. Aparece entonces la proyección de su deseo desde el que asoma Patagonia, como un espacio prefigurado, ordenado simbólicamente por ella, en tanto espacio de confin, otorgándole aquellas sensaciones exentas en su vida moderna:

"Mientras escribo, esos días vuelven vívidamente a mi mente otra vez y en mi fantasía contemplo otra vez, esa distante y desértica tierra, la tierra de las llanuras solitarias donde guanacos, avestruces y los indios andan a la aventura lejos del conocimiento de la humanidad y donde pasé un tiempo despreocupada y feliz, el que nunca podre olvidar" (Dixie, 1996: 251).

\section{Obras citadas}

Aguilera, Oscar y Tonko, José (2013). Relatos de viaje Kawésqar Nómadas Canoeros de la Patagonia Occidental. Temuco: Ofqui.

Burke, Edmund (1997) [1757]. Indagación sobre el origen de nuestras ideas acerca de lo sublime y de lo bello, Trad. Menene Gras Balaguer. Madrid: Tecnos.

Dixie, Florence (1880). Across Patagonia.London: Richard Bentley and Son. 
Dixie, Florence (1996) [1880]. A través de la Patagonia. Ed. Martinic, Mateo. Trad. Velasco, M. Teresa/Martelli, Rosanna. Punta Arenas: Ediciones de la Universidad de Magallanes.

Michel Foucault (2004). Des espaces autres. Empan No 54, pp. 12-19. Traducción mía.

Grace Paz, Gladys G.y Campbell, Duncan S. (eds.) (2015). Patagonia Bravia. Naturaleza, vidas y aventuras. Memorias Originales del baqueano William H. Greenwood. Santiago de Chile.

Kristeva, Julia (1991). Extranjeros para nosotros mismos. Barcelona: Plaza \& Janés.

Mackenzie, John M. (2005). "Imperios del viaje. Guías de viaje británicas e imperialismo cultural en los siglos XIX y XX". En: Salvatore, Ricardo (comp.): Culturas imperiales. Experiencia y representación en América, Asia y África. Rosario: Beatriz Viterbo, pp. 215-241.

Musters, George Chaworth (1871). At home with the Patagonians: A year's wanderings over untrodden ground from the Straits of Magellan to the Rio Negro. London: Murray.

Pratt, Mary Louise (2010)]. Ojos Imperiales. Literatura de Viajes y Transculturación. México: Fondo de Cultura Económica.

Spivak, G. (1998). ¿Puede hablar el sujeto subalterno? Orbis Tertius, No 6, pp. $175-235$.

Said, Edward W. (1990). Orientalismo. Madrid: Libertarias/Prodhufi,S.A.

Szurmuk, Mónica (2007). Miradas cruzadas. Narrativa de mujeres en la Argentina. 1850-1930. México: Instituto Mora.

Vicuña Mackenna, Benjamín (1877). Cambiaso. Santiago de Chile: Imprenta de la librería del Mercurio.

Williams, Raymond (2001). El campo y la ciudad. Prólogo a la edición en español de Beatriz Sarlo. Traducción de Alcira Bixio. Buenos Aires: Paidós. 

d

0

C

$\mathbf{U}$

m

e

n

$t$

0

S 
